success rate of cryorecanalization is very high $(90 \%)$. Thus cryorecanalization should be taken into account for a safe and fast treatment of endoluminal airway stenoses such as tracheal and bronchial manifestations of BALT lymphoma.

\section{References}

1. Bolliger CT, Sutedja TG, Strausz J, Freitag L. Therapeutic bronchoscopy with immediate effect: laser, electrocautery, argon plasma coagulation and stents. Eur Respir J. 2006;27:1258-71.
2. Vergnon JM, Huber RM, Moghissi K. Place of cryotherapy, brachytherapy and photodynamic therapy in therapeutic bronchoscopy of lung cancers. Eur Respir J. 2006;28:200-18.

3. Hetzel M, Hetzel J, Schumann C, Marx N, Babiak A. Cryorecanalization: a new approach for the immediate management of acute airway obstruction. $J$ Thorac Cardiovasc Surg. 2004;127:1427-31.

4. Kuper CF. Histopathology of mucosa-associated lymphoid tissue. Toxicol Pathol. 2006;34:609-15.

5. Ahmed S, Kussick SJ, Siddiqui AK, Bhuiya TA, Khan A, Sarewitz S, et al. Bronchial-associated lymphoid tissue lymphoma: a clinical study of a rare disease. Eur $J$ Cancer. 2004;40:1320-6.

\title{
New-onset heart failure caused by spontaneous papillary muscle rupture: Diagnosis with dual-source computed tomographic coronary angiography
}

Heon Lee, MD, PhD, ${ }^{\mathrm{a}, \mathrm{d}}$ Balazs Ruzsics, MD, PhD, ${ }^{\mathrm{a}}$ U. Joseph Schoepf, MD, ${ }^{\mathrm{a}, \mathrm{b}}$ Edward A. Stewart, DO, ${ }^{\mathrm{b}}$ Philip Costello, MD, ${ }^{\mathrm{a}}$ James L. Glenn, MD, ${ }^{\mathrm{b}}$ and John S. Ikonomidis, $\mathrm{MD}, \mathrm{PhD},{ }^{\mathrm{c}}$ Charleston, SC, and Seoul, Republic of Korea

Papillary muscle rupture is a rare cardiac emergency most frequently associated with acute myocardial infarction or blunt chest trauma. ${ }^{1,2}$ Once papillary muscle rupture has been diagnosed, urgent mitral valve replacement is indicated to correct the patient's hemodynamic deterioration. Here we present the case of a patient with spontaneous, complete posterior papillary muscle rupture in the absence of significant coronary artery disease, diagnosed with dual-source computed tomographic (CT) coronary angiography. To our knowledge, this is the first reported establishment of this diagnosis with cardiac CT.

\section{CLINICAL SUMMARY}

A 49-year-old woman with a history of hypertension and hyperlipidemia was admitted to the general medical service with a 1-month history of progressive cough, orthopnea, dyspnea on exertion, and increasingly limited exercise ability. Severe mitral valve regurgitation was found on echocardiography. Right and left heart catheterizations showed mild, nonobstructive coronary artery disease. In addition, severe mitral regurgitation and an elevated left ventricular filling pressure were confirmed, with moderate pulmonary

\footnotetext{
From the Department of Radiology, ${ }^{a}$ the Division of Cardiology, ${ }^{b}$ and the Department of Surgery, ${ }^{\mathrm{c}}$ Medical University of South Carolina, Charleston, SC, and the Department of Radiology, Seoul Medical Center, Seoul, Republic of Korea. ${ }^{d}$

Received for publication Jan 23, 2008; accepted for publication Feb 28, 2008.

Address for reprints: U. Joseph Schoepf, MD, Department of Radiology, Medical University of South Carolina, 169 Ashley Ave, Charleston, SC 29425 (E-mail: schoepf@musc.edu).

J Thorac Cardiovasc Surg 2009;137:e19-21

0022-5223/\$36.00

Copyright (c) 2009 by The American Association for Thoracic Surgery

doi:10.1016/j.jtcvs.2008.02.054
}

hypertension. On the basis of these findings, mitral valve replacement was recommended. A contrast-enhanced cardiac CT scan was scheduled to assess overall cardiac anatomy before valve replacement surgery and to evaluate further the etiology of the new-onset heart failure. ${ }^{3}$

Retrospectively electrocardiographically gated CT coronary angiography was performed with a dual-source CT scanner (Definition; Siemens, Forchheim, Germany) with a temporal resolution of $83 \mathrm{~ms}$ and $0.6 \times 32 \times 2$ collimation. At the time of the CT scan acquisition, the patient was in tachyarrhythmia, with heart rates ranging from 115 to 127 beats/min. Such heart rates would not have allowed diagnostic imaging of the heart with slower, previous generation 16or 64-slice CT scanners. In accordance with institutional policy, no pharmacologic rate control was used. The scan was enhanced with $75 \mathrm{~mL}$ iopamidol contrast medium (Isovue $370 \mathrm{mgI} / \mathrm{mL}$; Bracco, Princeton, NJ) injected at $6 \mathrm{~mL} / \mathrm{s}$. Multiphase axial reconstruction was performed with 0.75 mm section thickness for morphologic and functional analyses with multiplanar reformations, 3-dimensional volume rendering, and cineloop display.

CT coronary angiography showed nonobstructive stenosis in the mid left anterior descending coronary artery in good correlation with previous coronary catheterization. The left atrium and ventricle were enlarged, with left ventricular hypertrophy compatible with hypertensive heart disease. Lung reconstructions showed moderate pulmonary edema and pleural effusions. Image reconstruction during diastole and systole (Figure 1) showed a low-attenuation mass, inferior to the posterior leaflet of the mitral valve in the expected location of the posterior papillary muscle. On 

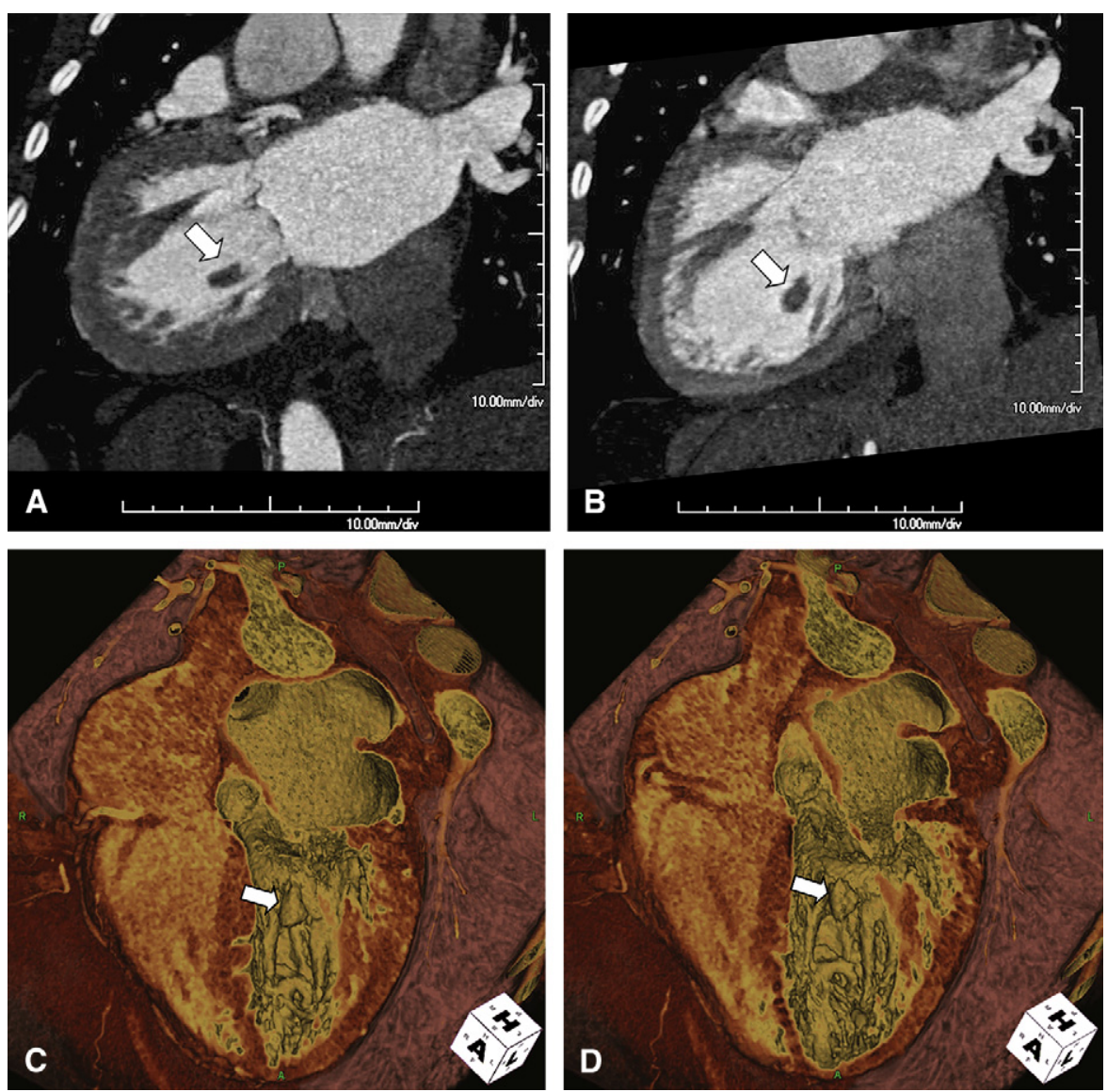

FIGURE 1. Two-chamber view multiplanar reconstructions (A and B) and 3-dimensional volume rendering in four-chamber view (C and D) during systole (A and C) and diastole (B and D) show low-attenuation mass (arrows) inferior to posterior leaflet of mitral valve in expected location of posterior papillary muscle. Anterior papillary muscle below anterior mitral valve leaflet is intact.

cineloop display, the mass moved in synchrony with the posterior mitral valve leaflet. On the basis of these findings, a diagnosis of papillary muscle rupture was made.

At mitral valve replacement surgery, the appearance of the mitral valve was essentially normal. The posterior papillary muscle head was attached to the chordae tendineae of the A3 portion of the anterior leaflet of the mitral valve and tethered to the remainder of the posterior papillary muscle by a thin fibrous band. Because the patient did not have known cardiac ischemia and her only cause of mitral regurgitation was the papillary muscle head rupture of unknown etiology, mitral valve replacement was performed with complete resection of the papillary muscle head. On pathologic examination, the mitral valve leaflet showed mild myxoid changes without bacterial vegetation. The head of the resected papillary muscle showed necrosis of its entire basal area.

\section{DISCUSSION}

Papillary muscle rupture is a rare but critical and often fatal mechanical complication seen most commonly with acute myocardial infarction or blunt trauma. Here, however, we describe a case of spontaneous, acute papillary muscle rupture in the absence of significant coronary artery disease. Moreover, we highlight the potential utility of recent generation cardiac CT scanners for noninvasive establishment of this diagnosis in the setting of new-onset heart failure, even in the presence of severe tachyarrhythmia and without ratecontrolling agents. As in our case, transthoracic echocardiography may not always detect this complication, especially when there is no evidence of underlying myocardial infarction or obstructive coronary artery disease. ${ }^{4}$

One possible explanation of spontaneous rupture of the papillary muscle head in this patient may lie in her left ventricular hypertrophy, which is recognized to increase the risk for papillary muscle ischemia. ${ }^{5}$ The left ventricular myocardium is more sensitive to hypoperfusion when hypertrophy is present. The subendocardium involving the papillary muscles is exposed to increased perfusion resistance, especially in the advanced stages of hypertrophic cardiomyopathy. ${ }^{5}$

In summary, in this patient dual-source CT enabled the noninvasive diagnosis of papillary muscle rupture, highlighting the potential utility of this imaging modality for elucidating rarer and unexpected etiologies of new-onset heart 
failure $^{3}$ and aiding in surgical planning. Further, this case illustrates that the spatial and temporal resolution of CT imaging has improved such that the diagnosis of coronary artery disease as well as of complex intracardiac pathology is now possible, even in the presence of severe tachyarrhythmia. In select cases, real-time dynamic CT imaging may eventually replace echocardiography and angiography and allow evaluation with a single test.

\section{References}

1. Nishimura RA, Schaff HV, Shub C, Gersh BJ, Edwards WD, Tajik AJ. Papillary muscle rupture complicating acute myocardial infarction: analysis of 17 patients. Am J Cardiol. 1983;51:373-7.
2. Devineni R, McKenzie FN. Acute mitral insufficiency resulting from blun chest trauma. J Thorac Cardiovasc Surg. 1983;85:797-8.

3. Hendel RC, Patel MR, Kramer CM, Poon M, Hendel RC, Carr JC. ACCF/ACR/ SCCT/SCMR/ASNC/NASCI/SCAI/SIR 2006 appropriateness criteria for cardiac computed tomography and cardiac magnetic resonance imaging: a report of the American College of Cardiology Foundation Quality Strategic Directions Committee Appropriateness Criteria Working Group, American College of Radiology, Society of Cardiovascular Computed Tomography, Society for Cardiovascular Magnetic Resonance, American Society of Nuclear Cardiology, North American Society for Cardiac Imaging, Society for Cardiovascular Angiography and Interventions, and Society of Interventional Radiology. J Am Coll Cardiol. 2006;48: 1475-97.

4. Kim TH, Seung KB, Kim PJ, Baek SH, Chang KY, Shin WS, et al. Images in cardiovascular medicine. Anterolateral papillary muscle rupture complicated by the obstruction of a single diagonal branch. Circulation. 2005;112:e269-70.

5. Waters BL. Clinical and pathologic factors contributing to acute papillary muscle ischemia. Arch Pathol Lab Med. 1990;114:601-4.

\section{False aneurysm after transapical aortic valve implantation}

Nawwar Al-Attar, FRCS, FETCS, PhD, Richard Raffoul, MD, Dominique Himbert, MD, Eric Brochet, MD, Alec Vahanian, MD, FRCP, and Patrick Nataf, MD, Paris, France

Video clip is available online.

\section{CLINICAL SUMMARY}

An 81-year-old man with severe aortic valve stenosis had repeated bouts of acute pulmonary edema (New York Heart Association class III). He had known triple-vessel coronary artery disease, chronic bronchitis, peripheral artery disease, and chronic atrial fibrillation. Echocardiography showed a mean gradient across a tricuspid aortic valve of $45 \mathrm{~mm}$ $\mathrm{Hg}$ with a calculated surface area of $0.38 \mathrm{~cm}^{2}$. It also showed functional mitral regurgitation (grade $2 / 4$ ) with heavy calcifications of the mitral annulus and severe pulmonary hypertension $(80 \mathrm{~mm} \mathrm{Hg})$. The left ventricular ejection fraction (LVEF) was calculated to be $15 \%$. Dobutamine stress echocardiography demonstrated a mild improvement of the LVEF and some contractile reserve. The EuroSCORE and Society of Thoracic Surgeons (STS) preoperative scores were $31 \%$ and $20 \%$, respectively. Conventional surgery was considered too risky and the patient was referred for

\footnotetext{
From the Bichat Hospital, Paris, France.

Received for publication June 18, 2008; accepted for publication July 6, 2008

Address for reprints: Nawwar Al-Attar, FRCS, FETCS, PhD, Department of Cardiac

Surgery, Hopital Bichat, 46 rue Henri Huchard, 75018 Paris, France (E-mail:

nalattar@gmail.com).

J Thorac Cardiovasc Surg 2009;137:e21-2

$0022-5223 / \$ 36.00$

Copyright (c) 2009 by The American Association for Thoracic Surgery

doi:10.1016/j.jtcvs.2008.07.018
}

transcatheter aortic valve implantation (TAVI). During his workup, he had low cardiac output and acute renal failure necessitating emergency aortic balloon valvuloplasty as a bailout procedure. After diminution of the gradient to $27 \mathrm{~mm} \mathrm{Hg}$ and improvement of renal function, TAVI was successfully performed through a left anterolateral thoracotomy via the transapical route with a balloon-expandable transcatheter xenograft (Edwards SAPIEN THV, Edwards Lifesciences, Irvine, Calif) $26 \mathrm{~mm}$ in diameter. An intra-aortic balloon pump was inserted after the procedure. Excess of anticoagulation contributed to a pericardial effusion of $600 \mathrm{~mL}$ that was drained 2 weeks after the operation. Echocardiography at 1 month demonstrated a functional prosthesis, negligible posterior leak $(<1 / 4)$, a mean gradient of $9 \mathrm{~mm} \mathrm{Hg}$, LVEF of $25 \%$, and pulmonary artery pressure of $35 \mathrm{~mm} \mathrm{Hg}$.

Three months after the procedure, the patient returned with a sudden-onset pulsating mass of $4 \mathrm{~cm}$ in diameter on the lateral aspect of the thoracotomy scar but was otherwise completely free of symptoms. Computed tomographic scan of the thorax showed a false aneurysm of the left ventricle of $50 \times 22$ $\mathrm{mm}$ dimension communicating with a pouch in the thoracic wall of $28 \times 27 \mathrm{~mm}$ diameter with enhancement at injection of contrast material (Figure 1). Echocardiography confirmed the presence of a left ventricular apical aneurysm with an LVEF of $34 \%$, good left ventricular kinetics, and a functional bioprosthesis; Doppler study confirmed flow within the aneurysmal sac (Figure 2 and Video E1). Surgical closure of the fistula was performed through sternotomy and cardiopulmonary bypass (CPB) accompanied by bypass grafting of the left anterior descending artery by the left internal thoracic artery. The patient made an uneventful recovery. 